\title{
Dental anxiety among Wisma Lincoln University College community
}

\author{
Misliah Ahmad, Tan Wen Wu
}

Faculty of Dentistry, Lincoln University College, 47301, Petaling Jaya, Selangor Malaysia

\begin{abstract}
Dental anxiety is common among people of all ages, which results in delay and avoidance of dental visit and eventually deterioration of oral health. The aim of this study is to assess the dental anxiety level among the community in Wisma Lincoln University College. A cross-sectional study was carried out from April to December 2018. A total of 186 participants were included in this study. The Modified Dental Anxiety Scale (MDAS) was used to assess participants' dental anxiety level. The prevalence of participants with severe anxiety level was $16.7 \%(\mathrm{n}=31)$, with Indian female being the highest number $(n=6,20 \%)$. Participants felt most anxious if they were to receive a local anesthetic injection, with a mean score of 2.04 for male and 3.76 for female. With regards to the aspects of dental treatment that make participants anxious, $74.7 \%(n=139)$ of the participants would feel anxious about extraction, followed by pain arising from treatment $(63.4 \%$, $\mathrm{n}=118)$ and fear of injury caused by dental instrument $(60.8 \%$, $\mathrm{n}=113$ ). In conclusion, $16.7 \%$ of the community in Wisma Lincoln University College were highly anxious, with Indian female being most anxious $(20 \%)$.
\end{abstract}

Keywords: dental anxiety, dental visit, Modified Dental Anxiety Scale

\author{
Received: \\ 28 April 2021 \\ Revised: \\ 30 June 2021 \\ Accepted: \\ 13 July 2021 \\ Published Online: \\ 31 July 2021
}

How to cite this article:
Misliah Ahmad, \& Tan, W. W.
(2021). Dental anxiety among
Wisma Lincoln University
College community. IIUM
Journal of Orofacial and Health
Sciences, 2(2), 93-98. Retrieved
from
https://doi.org/10.31436/ijohs.
$\underline{\text { v2i2.90 }}$
Article DOI:
https://doi.org/10.31436/ijohs.
v2i2.90
*Corresponding author
Address:
Faculty of Dentistry, Lincoln
University College, 47301,
Petaling Jaya, Malaysia

Email address:

wenwu@lincoln.edu.my

\section{Introduction}

Dental anxiety is very common among people of all ages, which results in delay or avoidance of dental visit and eventually deterioration of oral health (Armfield, 2013; Carter et al., 2014). Such people often have irregular dental attendance and only seek care in the case of an emergency (Armfield et al., 2007). Dental anxiety happens due to various reasons, such as traumatic childhood experience, fear of injection or unpleasant past dental visits (Beaton et al., 2014). It is not only a distressing problem for the public, but also for the dental practitioners as it can lead to increase chair time, diagnosis inaccuracy and negative dentist-patient relationship (Armfield et al., 2009).

Despite of the advances of modern dentistry, dental anxiety remains a huge problem to patients and dentists. According to Hmud and Walsh (2007), restorative dentistry is the main trigger for dental anxiety due to the sight of drills and needle, sound and sensation of drilling and smell of dental chemicals. Alternatively, atraumatic restorative treatment, air abrasion, chemomechanical caries removal and lasers are encouraged in anxious patients (Hmud \& Walsh, 2007). It is also noted that the time waiting for dental treatment is considered by many as anxiety provoking, as patients have the time to thinking about the worst 
possible outcome that can happen to them (Cohen et al., 2000).

Dental anxiety has been studied extensively worldwide, with a prevalence from 10 to $65 \%$ in different countries (Nicolas et al., 2007; Viinikangas et al., 2007; Hill et al., 2013; Bell et al., 2012; Kirova et al., 2010). Systematic review by Silveira et al. (2021) on adults found that the prevalence of dental fear and anxiety was $15.3 \%$, with $3.3 \%$ having severe dental fear and anxiety. The prevalence of dental anxiety among Malaysians has been reported to be around the same level. Study by Gunjal et al. (2017) among Malaysian students found that $16 \%$ of them had high level of dental anxiety, while another study among dental patients reported that $9.9 \%$ of them had high level of anxiety (Kueh, 2013). This study aims to assess the dental anxiety level among the community in Wisma Lincoln University College.

\section{Materials and Methods}

\section{Study design}

A cross-sectional study was carried out at Wisma Lincoln University College, involving staff, students, and visitors, from April to December 2018. A sample size of 186 was determined based on the prevalence of dental anxiety of $12.2-15.3 \%$ from the systematic review by Silveira et al. (2021) and Cianette et al. (2017) on adolescents and adults. Convenience sampling technique was used to select the participants for this study. An informed consent was obtained from all the participants prior to answering the questionnaire. Ethical approval was obtained from the Dental Research Ethics Committee, Lincoln University College (LUCethics/FDent/009/2018).

\section{Research tool}

The questionnaire used was the Modified Dental Anxiety Scale (MDAS) (Humphris et al., 2000), which has been validated and pre- tested extensively worldwide (Sitheeque $e t$ al., 2015; Humphris et al., 1995; Humphris et al., 2009). It has also been translated into the Malay version and tested among the local population (Sitheeque et al., 2015). In this study, both the English and Malay language were included in the MDAS questionnaire. The first part of the questionnaire consisted of 5 questions, assessing patients' anxiety level in relation to "thinking of seeing a dentist, sitting in the waiting room, having a tooth drilled, having teeth scaled and polished, and having a local anesthetic injection". Each question had five responses, using a 5-point Likert scales, ranging from not anxious, slightly anxious, fairly anxious, very anxious to extremely anxious, scored from 1 to 5 respectively. The patients would be categorized into low anxiety (5-11), moderately anxious (12-18) and severely anxious $(\geq 19)$, based on their scores. The second part of the questionnaire included 10 possible aspects of dental treatment that would make participants anxious, and they could choose more than one answer.

\section{Data collection and analysis}

A total of 186 questionnaires were distributed randomly to the staff, students, and visitors at Wisma Lincoln University College. Explanations were given to the participants regarding the objectives of the study. All queries from the participants were clarified before they filled in the questionnaires. The questionnaires were collected back upon completion and the data were analysed by applying descriptive and inferential statistical analysis, using SPSS version 24 . T-test was used to compare the mean score of each question in the MDAS between male and female.

\section{Results}

One hundred and eighty-six participants took part in this study. The demographic data of the participants is shown in Table 1. Most of the respondents were female $(55.9 \%, \mathrm{n}=104)$, Malay $(53.2 \%, \mathrm{n}=99)$ and 16 to 25 years old $(59.2 \%, \mathrm{n}=110)$. Table 2 presents the MDAS score categories of the 
participants. $16.7 \% \quad(n=31) \quad$ of the participants had severe anxiety level (MDAS score $\geq 19$ ). Table 3 shows the number of participants who obtained MDAS score of 19 and above based on race and gender. Indian female had the highest percentage $(20 \%$, $\mathrm{n}=6$ ) of high anxiety level, compared to other groups.

When looking at the individual aspect of the MDAS, the participants felt most anxious if they were to receive a local anesthetic injection, with a mean score of 2.04 for male and 3.76 for female $(\mathrm{p}<0.001)$, as shown in Table 4.

Table 5 shows 10 aspects of dental treatment that would make the participants anxious, and participants could choose more than one answer. The result showed that $74.7 \%(n=139)$ of the participants would feel anxious about tooth extraction, followed by pain arising from treatment $(63.4 \%, \mathrm{n}=118)$ and fear of injury caused by dental instrument $(60.8 \%, \mathrm{n}=113)$.

Table 1. Demographic data of the participants

\begin{tabular}{|lll|}
\hline Variables & Number (n) & Percentage (\%) \\
\hline Gender & 82 & 44.1 \\
Male & 104 & 55.9 \\
Female & & \\
Age & 110 & \\
$16-25$ & 32 & 59.2 \\
$26-35$ & 10 & 17.2 \\
$36-45$ & 17 & 5.4 \\
$46-55$ & 9 & 9.1 \\
$56-65$ & 8 & 4.8 \\
More than 65 & & 4.3 \\
Race & & \\
Malay & 99 & 53.2 \\
Chinese & 57 & 30.6 \\
Indian & 30 & 16.1 \\
Total & & $\mathbf{1 0 0}$ \\
\hline
\end{tabular}

Table 2. MDAS score categories of the participants

\begin{tabular}{|lllll|}
\hline & & Anxiety Level & Number (n) & Percentage (\%) \\
\hline MDAS score & $5-11$ & Low & 112 & 60.2 \\
& $12-18$ & Moderate & 43 & 23.1 \\
Total & $\geq 19$ & High & 31 & 16.7 \\
\hline
\end{tabular}

Table 3. Participants having MDAS score $\geq 19$, based on race and gender

\begin{tabular}{|c|c|c|c|c|c|c|}
\hline \multirow[b]{2}{*}{ Race } & \multicolumn{2}{|c|}{ Male } & \multicolumn{2}{|c|}{ Female } & \multicolumn{2}{|c|}{ Total } \\
\hline & $\mathrm{n}$ & $\%$ & n & $\%$ & n & $\%$ \\
\hline Malay & 2 & 2 & 16 & 16.2 & 18 & 18.2 \\
\hline Chinese & 3 & 5.3 & 4 & 7 & 7 & 12.3 \\
\hline Indian & 0 & 0 & 6 & 20 & 6 & 20 \\
\hline
\end{tabular}


Table 4. Mean score for individual aspect of the MDAS for all participants based on gender

\begin{tabular}{|c|c|c|c|}
\hline \multirow[t]{2}{*}{ Questionnaire Item } & Male & Female & \multirow[t]{2}{*}{ p-value (T-test) } \\
\hline & Mean (SD) & Mean (SD) & \\
\hline Thinking of seeing a dentist & $1.68(0.925)$ & $2.6(1.232)$ & $<0.001$ \\
\hline $\begin{array}{l}\text { Sitting in waiting room for } \\
\text { treatment }\end{array}$ & $1.83(0.965)$ & $2.68(1.284)$ & $<0.001$ \\
\hline About to have a tooth drilled & $1.94(1.194)$ & 3.47 (1.251) & $<0.001$ \\
\hline $\begin{array}{l}\text { About to have your teeth scaled } \\
\text { and polished }\end{array}$ & $1.76(1.058)$ & $2.96(1.473)$ & $<0.001$ \\
\hline $\begin{array}{l}\text { About to have a local anesthetic } \\
\text { injection }\end{array}$ & $2.04(1.195)$ & $3.76(1.356)$ & $<0.001$ \\
\hline
\end{tabular}

Table 5. Aspects of dental treatment that make participants anxious

\begin{tabular}{|lcc|}
\hline Aspects of dental treatment that make participants anxious & $\begin{array}{c}\text { Number } \\
\text { (n) }\end{array}$ & $\begin{array}{l}\text { Percentage } \\
\text { (\%) }\end{array}$ \\
\hline Pain arising from dental treatment & 118 & 63.4 \\
Putting dental instrument into the mouth & 90 & 48.4 \\
Gagging feeling & 46 & 24.7 \\
Tiring jaw after prolonged mouth opening & 60 & 32.3 \\
Worried having a lot of dental treatment & 50 & 26.9 \\
Worried for the cost of dental treatment & 84 & 45.2 \\
Insufficient information about dental procedures & 72 & 38.7 \\
Fear of injury caused from dental instruments & 113 & 60.8 \\
Dislike the feeling of numbness from anesthesia & 72 & 38.7 \\
Tooth extraction & 139 & 74.7 \\
\hline
\end{tabular}

\section{Discussion}

The present study was conducted to investigate the dental anxiety level among Wisma Lincoln University College community, using the MDAS questionnaire. In this study, $16.7 \%$ of the participants were considered to have high dental anxiety level, with Indian female being the most anxious (20\%). However, according to Schuurs and Hoogstraten (1993) higher anxiety score among women did not necessarily mean that they were more anxious, but they expressed their anxiety level more readily than men. Similar results were observed in Adult Dental Survey 2009 in the United Kingdom (Hill et al., 2013), with $12 \%$ of the population having extreme dental anxiety. Studies conducted in other European countries among French and Finnish adults revealed that the prevalence of adults with severe dental anxiety were slightly lower, with the prevalence of $7.3 \%$ and $8 \%$ respectively
(Nicolas et al., 2007; Viinikangas et al., 2007).

When compared to local studies, contrasting results are seen. Study by Sitheeque et al. (2015) among dental patients at Hospital Universiti Sains Malaysia found that only $3.5 \%$ of them had high level of dental anxiety, while in a similar study among patients attending dental clinic Oya, Sibu, $9.9 \%$ of them reported to have high level of dental anxiety (Kueh, 2013). The difference in the results could be attributed by patients' oral health awareness and their frequency of exposure to clinical and dental settings. Nevertheless, in a more recent study among 1024 Malaysian students using the MDAS, the percentage of students with high level of dental anxiety was 16.3\% (Gunjal et al., 2017).

With respect to individual question in the MDAS for all participants, the highest mean score was seen to be associated with 
intraoral anesthetic injection for both male and female (2.04 and 3.76). Such finding is consistent with the literature, as needle injection is often cited as the main cause of dental anxiety (Hakim and Razak, 2014; Siddiqui et al., 2016; Al-Omari \& Al-Omiri, 2009; Yoshida et al., 2009; Gunjal et al., 2017). This is most likely because injection can inflict pain, and dental anxiety often arises due to anticipation of pain during the procedure. Nevertheless, newer technology such as Computer Assisted Relaxation Learning (CARL) (Heaton et al., 2013), a selfpaced, computerized program based on systematic desensitization has proven to be effective in helping patients to reduce their self-reported, injection specific dental anxiety.

Finally, when asked about the aspects of dental treatment that make participants anxious, $74.4 \%$ of the participants claimed that tooth extraction would make them anxious, followed by pain arising from dental treatment (63.4\%) and fear of injury caused by dental instrument (60.8\%). Thus, it is important to always assess patients' level of dental anxiety prior to dental treatment, explain each step of the procedure to them clearly and adopt a supportive, gentle, and sympathetic approach to help patients to relax and adapt to the clinical settings.

Dental anxiety has become a major barrier to assessing dental care and maintenance of good oral health by many people (Krishnan et al., 2020; Freeman, 1999; Milgrom et al., 2010; Hill et al., 2013). Individual with dental anxiety often find themselves being trapped in a vicious cycle of avoiding dental visit, seeking care only when there is pain and eventually needing invasive dental treatment (Armfield et al., 2007; Armfield, 2013). These people also report to have very bad oral health (Armfield et al., 2009). Thus, identifying ways in which these people can be supported is vital, to increase their utilization of dental care. For example, setting up specialized dental clinic to manage patients with dental anxiety would help to alleviate their dental anxiety level and increase their uptake of dental care.
Several limitations were present in this study. The results from the cross-sectional study did not demonstrate a causal relationship. The sample size was small and only taken from Wisma Lincoln University College. Thus, it is not representative of the whole population. Also, self-reported questionnaire was prone to recall bias and social desirability bias, where participants tend to hide their feeling of dental anxiety.

\section{Conclusions}

Based on the study, $16.7 \%$ of the community in Wisma Lincoln University College were highly anxious, with Indian female being most anxious (20\%). Most participants would feel anxious if they were to have a tooth extraction $(74.7 \%, n=139)$, followed by pain arising from dental treatment (63.4\%, $\mathrm{n}=118)$. Apart from psychotherapeutic and pharmacological interventions, elimination of dental anxiety can be achieved by dental education and promoting awareness about oral health.

\section{Acknowledgements}

The author would like to thank all the staff and students from Lincoln University College, Malaysia for their support and help, to make this study a success.

\section{References}

Al-Omari, W. M. \& Al-Omiri, M. K. (2009). Dental anxiety among university students and its correlation with their field of study. Journal of Applied Oral Science, 17(3), 199-203.

Armfield, J. M. (2013). What goes around comes around: revisiting the hypothesized vicious cycle of dental fear and avoidance. Community Dentistry and Oral Epidemioly, 41(3), 279-287.

Armfield, J. M., Slade, G. D. \& Spencer, A. J. (2009). Dental fear and adult oral health in Australia. Community Dentistry and Oral Epidemioly, 37(3), 220-230.

Armfield, J. M., Stewart, J. F. \& Spencer, A. J. (2007). The vicious cycle of dental fear: exploring the interplay between oral health, service utilization and dental fear. BMC Oral Health, 7, 1.

Beaton, L., Freeman, R. \& Humphris, G. (2014). Why are people afraid of the dentist? Observations and 
explanations. International journal of the Kuwait University, Health Science Centre, 23(4), 295-301.

Bell, R. A., Arcury, T. A., Anderson, A. M., Chen, H., Savoca, M. R., Gilbert, G. H., et al. (2012). Dental anxiety and oral health outcomes among rural older adults. Journal of Public Health Dentistry, 72(1), 53-59.

Carter, A. E., Carter, G., Boschen, M., Alshwaimi, E. \& George, R. (2014). Pathways of fear and anxiety in dentistry: A review. World Journal of Clinical Cases, 2(11), 642-653.

Cianetti, S., Lombardo, G., Lupatelli, E., Pagano, S., Abraha, I., Montedori, A., et al. (2017). Dental fear/anxiety among children and adolescents. A systematic review. European Journal of Paediatric Dentistry, 18(2), 121-130.

Cohen, S. M., Fiske, J. \& Newton, J. T. (2000). The impact of dental anxiety on daily living. Britist Dental Journal, 189(7), 385-90.

Freeman, R. (1999). Barriers to accessing dental care: Patient factors. British Dental Journal, 187(3), 141144.

Gunjal, S., Pateel, D. G. \& Parkar, S. (2017). Dental Anxiety among Medical and Paramedical Undergraduate Students of Malaysia. International Journal of Dentistry, 2017, 4762576.

Hakim, H. \& Razak, I. A. (2014). Dental Fear among Medical and Dental Undergraduates. The Scientific World Journal, 2014, 747508.

Heaton, L. J., Leroux, B. G., Ruff, P. A. \& Coldwell, S. E. (2013). Computerized dental injection fear treatment: a randomized clinical trial. Journal of Dental Research, 92(7), 37S-42S.

Hill, K. B., Chadwick, B., Freeman, R., O'sullivan, I. \& Murray, J. J. (2013). Adult Dental Health Survey 2009: relationships between dental attendance patterns, oral health behaviour and the current barriers to dental care. British Dental Journal, 214(1), 25-32.

Hmud, R. \& Walsh, L. (2007). Dental anxiety: causes, complications and management approaches. . International Dentistry South Africa, 9(5), 6-16.

Humphris, G. M., Dyer, T. A. \& Robinson, P. G. (2009). The modified dental anxiety scale: UK general public population norms in 2008 with further psychometrics and effects of age. BMC Oral Health, 9(1), 20.

Humphris, G. M., Freeman, R., Campbell, J., Tuutti, H. \& D'souza, V. (2000). Further evidence for the reliability and validity of the Modified Dental Anxiety Scale. International Dental Journal, 50(6), 367-370.

Humphris, G. M., Morrison, T. \& Lindsay, S. J. (1995). The Modified Dental Anxiety Scale: validation and United Kingdom norms. Community Dental Health, 12(3), 143-150.

Kirova, D. G., Atanasov, D. T., Lalabonova, C. K. \& Janevska, S. (2010). Dental anxiety in adults in Bulgaria. Folia Medica (Plovdiv), 52(2), 49-56.

Krishnan, L., C. S, A. \& Kumar, P. D. M. (2020). Barriers to access dental care services among adult population: A systematic review. Journal of Global Oral Health, 3(1), 54-62.

Kueh, T. S. 2013. A cross-sectional survey on dental anxiety among adult patients in dental clinic Oya,
Sibu. Sibu Research Seminar 2013. Sibu, Sarawak, Malaysia.

Milgrom, P., Newton, J. T., Boyle, C., Heaton, L. J. \& Donaldson, N. (2010). The effects of dental anxiety and irregular attendance on referral for dental treatment under sedation within the National Health Service in London. Community Dentistry and Oral Epidemiology, 38(5), 453-459.

Nicolas, E., Collado, V., Faulks, D., Bullier, B. \& Hennequin, M. (2007). A national cross-sectional survey of dental anxiety in the French adult population. BMC Oral Health, 7(1), 12.

Schuurs, A. H. \& Hoogstraten, J. (1993). Appraisal of dental anxiety and fear questionnaires: a review. Community Dentistry and Oral Epidemioly, 21(6), 329-339.

Siddiqui, T., Wali, A., Abdullah, H., Khan, F. N., Tanvir, R. \& Siddiqui, M. (2016). Evaluation of fear of injections and its association with avoidance of dental treatment. Journal of Restorative Dentistry, 4(3), 81-85.

Silveira, E. R., Cademartori, M. G., Schuch, H. S., Armfield, J. A. \& Demarco, F. F. (2021). Estimated prevalence of dental fear in adults: A systematic review and meta-analysis. Journal of Dentistry, 108, 103632.

Sitheeque, M., Massoud, M., Yahya, S. \& Humphris, G. (2015). Validation of the Malay version of the Modified Dental Anxiety Scale and the prevalence of dental anxiety in a Malaysian population. Journal of Investigative and Clinical Dentistry, 6(4), 313320.

Viinikangas, A., Lahti, S., Yuan, S., Pietilä, I., Freeman, R. \& Humphris, G. (2007). Evaluating a single dental anxiety question in Finnish adults. Acta Odontologica Scandinavica, 65(4), 236-240.

Yoshida, T., Milgrom, P., Mori, Y., Nakai, Y., Kaji, M., Shimono, T., et al. (2009). Reliability and crosscultural validity of a Japanese version of the Dental Fear Survey. BMC Oral Health, 9(1), 17. 